\title{
GERAÇÃO X: ADULTOS INFANTILIZADOS - UMA ANÁLISE DO FENÔMENO
}

\author{
Andreia Perroni Escudero ${ }^{1}$
}

\section{RESUMO}

Por tratar-se de uma tendência cuja emergência se deu após os anos 90, a adultescência é trazida como uma característica da geração $X$. O texto aborda situações comuns que ratificam esse puerismo e relaciona-o com os conteúdos midiáticos vivenciados na infância deste grupo. Além disso, reflete sobre a possibilidade de seus hábitos de consumo atuais serem uma "válvula de escape" das tensões impostas pela vida moderna, uma fuga que os leva nostalgicamente para a infância e a seu mundo de personagens, a produtos e a comportamentos formatados e difundidos pelos meios de comunicação.

Palavras-chave: Geração X; Meios de comunicação; Consumo; Adultescência.

\begin{abstract}
As a trend whose emergence occurred after the nineties, adultescence, a neologism that unites adults in adolescence, is taken as a characteristic of $\mathrm{X}$ generation. This text covers common situations that confirm their puerilism and relates it to the media content of this group experienced in childhood. Moreover, it reflects on the possibility of their spending habits today are way to forget the stresses imposed by modern life, a trail that leads back nostalgically to their childhood and world of characters, products and behaviors formatted the media a phase in which they were happy.
\end{abstract}

Keywords: Generation X; mass media; consumption; adultescence.

\section{INTRODUÇÃO}

Certa vez Nelson Rodrigues escreveu em uma crônica que o Brasil de 1920 era uma paisagem de velhos: “(...) os moços não tinham função, nem destino. A época não suportava a mocidade" (1993, p. 158). Para tentar amenizar o fato de "ser jovem", havia um esforço coletivo desta classe no sentido de disfarçar seu tempo cronológico e aparentar mais idade. Era comum um homem de 25 anos cultivar e zelar por seu bigode, optar por roupas escuras e discretas e adotar o guarda-chuva ou a bengala como acessório inseparável, para ser identificado como um representante da classe dos 40 e 50 anos. Para se ter o respeito e voz ativa perante àquela sociedade, era necessário pertencer à categoria dos "senhores".

\footnotetext{
${ }^{1}$ Doutora em Comunicação e Semiótica (PUC-SP), professora da Universidade Anhembi Morumbi.
} 
Através do relato acima, pode-se perceber a grande discrepância na forma como a sociedade do início do século XX percebia o período juvenil se comparada com os dias atuais, em que a juventude no indivíduo é condição favorável para aceitação e admiração social. E não basta “aparentar” juventude. O fenômeno vai além da estética. Hoje se vive a juventude através dos hobbies que se adota, pelas formas de entretenimento, através da maneira de se socializar, pela forma de se comunicar, pelas escolhas que se faz, e tudo isto independente da faixa etária. Pode-se adotar a juventude como estilo de vida aos 80 anos.

Por não se tratarem de casos isolados, muitos são os exemplos que ratificam esta tendência, demonstrando como as fronteiras entre o comportamento adolescente e adulto estão fluídas. O indivíduo maduro e os símbolos que o representam estão em plena transformação.

$\mathrm{Na}$ grande imprensa muitas matérias têm sido veiculadas ${ }^{2}$, dando nome e detalhes sobre o juvenilização ${ }^{3}$ do adulto contemporâneo, tão facilmente identificável no meio social, no meio artísitico, entre personalidades da política, do esporte, da música, entre amigos e familiares de cada um de nós. Por exemplo, na categoria esportiva o tenista Guga, 36 anos, visto como um eterno garotão na maneira de encarar a vida e de se divertir, com seu sorriso maroto e cabelos despentados comendo bananas nos grandes prêmios ou surfando nas horas de lazer; entre políticos um bom exemplo foi Fernando Collor e seus esportes radicais, completamente dissonante do perfil de um presidente da República, porém com um apelo muito eficiente; entre empresários a família Diniz eternamente jovem na aparência e em suas preferências por "brinquedinhos" caros, que em certa ocasião pagou por uma bicicleta em leilão $\mathrm{R} \$ 80.000,00$, além de colecionar carros de corrida, etc.; a apresentadora Xuxa, 48 anos, e seu jeito menina de ser, vestir e cantar; até

\footnotetext{
${ }^{2}$ Alguns exemplos: "Os alimentos que podem nos manter jovens por mais tempo", 02/06/2004; "A geração sem idade - Mulheres e homens maduros que já desfrutam dos formidáveis avanços da medicina na conservação da Juventude", 15/07/2009; "A sedução dos jovens", Folha de S. Paulo, 20/09/1998; "Os exageros da plástica", Veja, 06/03/2002; "Adolescendo - Síndrome de Peter Pan para conquistar o público teen", Diário Popular de Pelotas, 28/01/2006; "A idade real - seu coração, cérebro, ossos, músculos podem ficar mais jovens por muito mais tempo", 24/05/2006; "Uma frenética necessidade de se sentir sempre jovem", programa "Mais Você" da Rede Globo, 21/05/2007; "Adolescência Espichada", Veja, Comportamento, Edição 2024, 5/09/2007; "Porque eles nunca crescem: a síndrome de Peter Pan dos milionários de calção...", Veja, 04/02/2009; "Corpo: 80\% da saúde e longevidade dependem apenas de quanto a pessoa conhece seu organismo", 18/11/2009.

3 "A juvenilização corresponde a um retardamento ontogênico, isto é, 'ao prolongamento do período biológico da infância e da adolescência, e mesmo a uma falta de acabamento ontogenético, isto é, a falta de acabamento na substituição das características juvenis pelas adultas"” (MORIN: 2000, p.83).
} 
mesmo na religião, como o pastor Rinaldo de Seixas Pereira, fundador da Igreja neopentecostal Bola de Neve Church, que aos 39 anos apresenta um figurino surfwear, cabelos espetados e que adora surfar, ou então, no caso de Robson Rodovalho, de 50 anos, bispo da Igreja Sara Nossa Terra, que além de ser judoca e praticar corrida e musculação, introduziu no templo junto com sua esposa aulas de hip hop, capoeira e funk.

Seguem alguns outros fatos que ratificam a tendência descrita:

- Hoje em dia é comum nos depararmos com grupos de indivíduos fantasiados em espaços públicos, como em shopping centers ou feiras temáticas. Esta prática denominada cosplays ${ }^{4}$ é compartilhada por pessoas que se trajam e vivenciam personagens do cinema, interpretam cenas de seus filmes preferidos, além de diversos outros personagens fictícios, sem nenhum constrangimento. Nem estamos falando de crianças em que este comportamento seria completamente corriqueiro. Estamos falando em indivíduos em idade adulta que adotaram tais encenações como um hobby.

- Os cantores brasileiros Paula Toller, 49 anos, e Lulu Santos, 58 anos, por exemplo, podem ser considerados representates da categoria dos jovens tardios. Suas canções retratam problemas juvenis e paixões platônicas, embora ambos já tenham há muito passado dos 20 anos. Ambos incorporam típicos adolescentes na maneira de se vestir e de se comportar sobre os palcos, sem causar a mínima estranheza no púbico. Não cabe aqui julgar se faz parte de um posicionamento artístico ou se na vida real eles possuem tais características. O objetivo é mostrar que tal forma de comportamento já faz parte da cultura contemporânea e não traz qualquer tipo de estranhamento por parte do público. Muito pelo contrário, traz admiração e maior aceitabilidade social, principalmente perante o público mais jovem.

- O New York Times Book Review publicou em agosto de 2000 que 30\% dos três primeiros livros da série Harry Potter foram comprados por e para leitores que tinham 35 anos ou mais. Outra pesquisa, realizada em maio de 2001,

\footnotetext{
${ }^{4} \mathrm{O}$ cosplay (costume player) é um hobby que consiste em fantasiar-se de personagens oriundos, em geral, de quadrinhos, games e desenhos animados japoneses. A prática do cosplay também engloba personagens pertencentes ao vasto universo do entretenimento, como filmes, séries de TV, livros e animações de outros países. Em menor escala há aqueles que se caracterizam como figuras históricas ou de criações originais. Uma das principais características do cosplay é que o praticante, além de criar os trajes, também interpreta o personagem caracterizado, reproduzindo os traços de personalidade como postura, falas e poses típicas. O hobby costuma ser praticado em eventos que reúnem fãs desse universo, como convenções de anime e games. (http://www.cosplaybr.com.br, em 25/07/2011).
} 
mostrou que entre os 1.373 entrevistados que estavam planejando comprar produtos Harry Potter 57\% eram crianças e 43\% adultos; e entre os adultos, $32 \%$ admitiram estar comprando algum desses produtos para si próprios (apud Borelli, 2008, p. 62).

- Nos campi universitários também há vestígios deste juvenilização ${ }^{5}$. É cada vez maior o número de jovens que adiam sua formatura universitária (optando por intercâmbios ou iniciando outros cursos) a fim de adiar também as responsabilidades que se apresentam após este ritual de passagem: se tornar adulto, arrumar emprego, se adequar ao mercado de trabalho por si mesmo, sem o auxílio da faculdade, etc. Vinícius de Freitas, de 23 anos, terminaria o curso de administração na PUC no segundo semestre de 2005, mas adiou a formatura para julho de 2006, pois conseguiu um estágio e não quer desperdiçar a oportunidade: "Eu pensava: vou me formar e fazer o que depois? Vaga de trainee é difícil. Preferi adiar a formatura. Farei só a disciplina estágio supervisionado II no semestre que vem."

- A Consumer Electronics Association publicou em 2006 pesquisa $^{6}$ na qual desmitifica a ideia de que videogame é coisa de criança, pelo menos nos EUA. De acordo com a Associação, um terço dos jogadores de games são adultos, que passam 10 horas semanais, ou mais, em frente de seu PC ou console doméstico. Isso inclui jogadores entre 25 e 34 anos.

- Apesar de muitos serem profissionais bem-sucedidos que já passaram dos 30 anos, acabam não resistindo ao prazer de colecionar bonecos e miniaturas. Com uma infinidade de opções no mercado (muitas delas verdadeiras fortunas), estes fãs acabam fazendo o que for necessário para aumentar o acervo. As vitrines das lojas especializadas não restringem aos super-heróis, estendem suas linhas aos personagens de filmes, animes e mangás japoneses, seriados de televisão, bandas de rock, cantores e esportistas. Este público adulto já representa mais de $40 \%$ dos compradores das miniaturas, que custam entre $\mathrm{R} \$ 60$ e $\mathrm{R} \$ 120$. Na lista dos mais procurados estão os personagens do seriado Lost, dos filmes Matrix, O Senhor dos Anéis, Guerra nas Estrelas e

\footnotetext{
${ }^{5}$ Conforme matéria veiculada no site http://noticias.universia.com.br, em 10/11/2005.

${ }^{6}$ Informação divulgada no site http://jogos.uol.com.br/ultnot/multi/ult530u3930.jhtm, em 23/03/2006.
} 
Harry Potter, as bandas Beatles e Led Zeppelin, além dos atletas Ronaldinho Gaúcho e David Beckham?

- Também não é raro nos últimos anos adultos que escolhem para seus aniversários temas juvenis que se referem ao cinema ou a personagens de desenhos das gerações às quais eles estão mais familiarizados, como as dos anos 60, 70 e 80, resgatando de uma forma nostálgica a infância/adolescência ${ }^{8}$. Segue um exemplo 9 : o funcionário público Cristiano Rodrigues Montemor preparou para sua mulher Virgínia uma festa surpresa para comemorar seus 29 anos. Os dois realmente voltaram à infância. Depois de muito tempo longe de brinquedos, Cristiano, Vírginia e os convidados se divertiram no escorregador, trenzinho, labirinto, entre outras atrações. Dos cerca de 60 convidados, apenas cinco eram crianças. "Todo mundo brincou", conta Cristiano. A decoração do espaço teve como tema a personagem japonesa Hello Kitty, uma das favoritas de Virgínia.

É impossível enumerar todos os fatores que podem ser indícios de um adulto vivendo uma adolescência tardia, até porque não há um conjunto estabelecido de situações que determine tal status, também não se tem a intenção aqui de catalogá-los. Porém, apenas para constar, todo comportamento, conduta ou estética discrepantes ao estereótipo criado e disseminado nos últimos séculos pela sociedade relacionado ao indivíduo "adulto", substituídos por ações/hobbies/comportamentos dignos da fase juvenil, podem ser considerados traços de um indivíduo juvenilizado.

\subsection{BABY BOOMERS E GERAÇÃO X - DE UMA PRÉ-DISPOSIÇÃO DE ADOTAR IMAGENS JUVENIS A COMPORTAMENTO EPIDÊMICO SÓCIO-CULTURAL}

\footnotetext{
When I see my parents fight

I don't wanna grow up

They all go out and drinkin all night

${ }^{7}$ Matéria divulgada na Revista Isto É, edição 2005, de 04/2008 - seção Comportamento.

${ }^{8}$ http://www.guiasuafesta.com.br/site/artigos/festa-para-adultos-\%E2\%80\%93-como-produzir-festatematicas-para-adultos em 20/05/2010.

${ }^{9}$ http://www.guiadebuffetsinfantis.com.br/exibe edicoes.php?id_edicao=27\&id_indice=16, “ Buffets Infantis investem em festas para todas as idades", acesso em 16/01/2012.
} 
I don't wanna grow up

I'd rather stay here in my room

Nothing out there but sad and gloom

I don't wanna live in a big ol tomb on Grand St.

When I see the 5 0' clock news

I don't wanna grow up

Comb their hair and shine their shoes

No I don't want to grow up ${ }^{10}$

(Ramones)

A música é uma das formas de expressão mais viscerais da humanidade, pois a inspiração para se compor está na maioria dos casos diretamente ligada ao estado de espírito do artista. Assim, o contex to no qual o compositor está inserido, o que vê o que ouve e o que sente são determinantes para construir sua obra.

Porém, o que leva milhões de indivíduos a comprarem os mesmos CDs e cantarem as mesmas letras? As músicas que normalmente viram grandes hits de sucesso contemplam fatos geradores de projeções e identificações que fazem com que o indivíduo sinta-se o próprio compositor daquela obra. Ou seja, compartilham as situações, sentimentos, problemas, sonhos, entre outros.

"I don’t wanna grow up" ficou conhecida mundialmente através da regravação realizada pelo conjunto Ramones em 1995 e virou hino dos adolescentes da época.

Como se pode perceber, sua letra reflete um desejo de não avançar para o próximo estágio da vida, de não tornar-se adulto como forma de evitar os desprazeres e responsabilidades acarretadas pelo próximo ciclo, como acordar cedo, pegar condução lotada, ter que conviver com a violência, as brigas inerentes aos relacionamentos maduros, etc. Desejo este compartilhado pelos milhares de jovens que a cantavam há 17 anos.

\footnotetext{
${ }^{10}$ A música "I Don`t Wanna Grow Up” foi regravada pelo conjunto americano Ramones em 1995, álbum Adios Amigos, sendo sua gravação original do compositor e cantor John Waits. Segue tradução do trecho acima citado: (...) Quando vejo meus pais brigando/ Eu não quero crescer / Todos saem e bebem a noite toda / Eu não quero crescer / Fico bastante em meu quarto / Nada lá fora além de tristeza e obscuridade / Eu não quero viver numa velha e grande tumba numa rua principal / Quando vejo as notícias das cinco horas / Eu não quero crescer / Pentear cabelos e engraxar sapatos / Eu não quero crescer / Ficar dando voltas em minha velha cidade natal / Eu não quero gastar dinheiro / Eu não quero pegar empréstimo / Nem gastar meus dedos até os ossos no trabalho / Eu não quero voar numa vassoura / Me apaixonar, casar e então a explosão / Como diabos isto aconteceu tão rápido?
} 
E de fato, os adolescentes que cantavam em coro a canção, hoje na faixa dos 35 anos, realizaram, pelo menos parcialmente, seu desejo: continuam de alguma forma adolescentes.

Mantém seus ídolos da infância, por exemplo, lotam as salas de cinema para assistirem produções como Batman, Homem Aranha, Super Homem, X-Men, etc. Continuam apreciando as refeições ligeiras e de má qualidade, que inclui comer salgadinhos, hambúrgueres e fritas, enfim, mantêm aspectos juvenis em suas vidas. Essa geração, chamada por alguns de Geração X, tem suas peculiaridades.

Para os mercadólogos, classificar as gerações significa poder dialogar com seus consumidores de forma dirigida, pois cada geração apresenta características semelhantes, tiveram, por exemplo, os mesmos ídolos, viveram a mesma fase da política, cantaram as mesmas músicas, consumiram produtos parecidos, etc. Seguem peculiaridades da Geração $X$ que, segundo esta análise, foram determinantes na contextualização do emergir deste "adultescente"

Pela divisão proposta pelos pensadores que criaram a teoria das gerações, trata-se de pessoas nascidas na segunda metade de 1960 até 1979, período da Guerra Fria. Esses indivíduos se apropriaram das conquistas da geração anterior, os Baby Boomers, e vivem em uma busca do prazer sem culpa. São individualistas, apaixonados pelos estereótipos criados pelos meios de comunicação, sofrem grande influência dos avanços do marketing e da publicidade. Talvez porque desde a infância esta geração está em contato com conteúdos midiáticos, através de anúncios de alimentos, brinquedos, programações específicas e entretenimento, entre outros.

Um exemplo é que em 1977 foi lançado o Filme Guerra nas Estrelas e pela primeira vez houve uma explosão no consumo infantil. Os criadores do filme e principalmente o produtor cinematográfico George Lucas acreditavam que o merchandising de um filme poderia ser tão lucrativo quanto o próprio filme. A aposta se

11 Segundo "Um Glossário para os Anos 90”, desenvolvido por David Rowan (Editora Prion), colunista de comportamento do jornal britânico The Gardian, no verbete é destacado: "Adultescente" pessoa imbuída de cultura jovem, mas com idade suficiente para não o ser. Geralmente entre os 35 e 45 anos, os adultescentes não conseguem aceitar o fato de estarem deixando de ser jovens. Calligaris (1998) também traz à reflexão este neologismo: “O adultescente seria um adulto que se faz de adolescente, um adulto que mantém estilo de vida próprio de adolescente. Ao ser o ideal do tempo da liberdade de escolher, a adolescência, como símbolo da modernidade, seria inevitavelmente o ideal, também, da vida adulta. Assim: 'estar adolescente' é um traço normal da vida adulta moderna. É uma maneira de afirmar a possibilidade de ainda vir a ser outro”. 
concretizou, pois a produção bateu recorde de bilheteria atingindo a casa dos US\$ 300 milhões e os bonecos, naves e jogos dobraram esta cifra ${ }^{12}$.

Fórmula testada, na década de 80 inicia-se o movimento de criação de desenhos para a TV justamente para vender bonecos: He Man, Ursinhos Carinhosos, Moranguinho e seus amigos, Smurphs, foram criados com este intuito e eram conhecidos como propagandas de longa duração.

Concomitantemente, mães no mercado de trabalho e pais com jornada prolongada em seus escritórios, além do alto índice de divórcios, desenvolveram uma necessidade de suprir a ausência com os objetos de consumo que os filhos começavam a solicitar.

Na década de 90, grandes empresas traziam o foco para o público infantil e pesquisadores de marketing começam a se infiltrar neste mundo observando sua forma de brincar; comer; se relacionar; se divertir exatamente para descobrir o que essas crianças queriam, precisavam e principalmente o caminho para fazer chegar o objeto até elas.

Invadiram a sua individualidade como um aliado, porém, todas as dicas dadas por este público foram usadas para a sua própria persuasão na compra. Através da análise de seus hábitos, preferências, gostos e assuntos, psicólogos e psicosociólogos traçam os sonhos em comum além da forma como persuadirem seus pais a conseguirem o que queriam. "As campanhas mais bem sucedidas são as que apresentam às crianças a linguagem apropriada a ser usada na hora da amolação"13.

Assim, desde cedo esta geração aprendeu a consumir com os estímulos embutidos em propagandas e programas de TV.

No Brasil, uma campanha publicitária inesquecível com este enfoque foi desenvolvida no final dos anos 70 e veiculada até os anos 90: "Não Esqueça a Minha Caloi". A Campanha consistia em distribuir pela casa diversos "lembretes", tais como paletó do pai, bolsa da mãe, gavetas, para que os adultos não esquecessem o presente desejado. A própria Caloi fornecia os bilhetes e sugeria os lugares mais eficientes para os pais encontrá-los.

\footnotetext{
${ }^{12}$ Conforme documentário "Pequenos Grandes Consumidores escrito, dirigido e produzido por Ann-Marie Redmond e Nathalie Bibeau para a CBC Documentary Unit, e veiculado por GNT em 20/10/2006 .

${ }^{13} \mathrm{Em} 1998$ foi desenvolvido o primeiro estudo por uma empresa americana de pesquisa de marketing denominado "Pais, crianças que amolam e decisões ao ir às compras". Este estudo não tinha como objetivo ajudar os pais a lidar com estas amolações e sim para que elas fossem realizadas de maneira mais efetiva para levarem os pais às compras. Segundo o estudo, uma amolação eficiente aumenta entre $21 \%$ a $41 \%$ as vendas em todos os setores como parques, cinemas, restaurantes, vestuário, alimentos, etc. Pelo estudo, $70 \%$ dos pais se deixam levar pela "amolação"
} 
Em 1991 a "Nostradamus" do marketing como é chamada a pesquisadora americana Faith PopCorn (Faith Beryl Plotkin) lança o livro "O Relatório PopCorn” com as tendências de comportamento e consumo para a década de 90 e início do século XXI. Entre as tendências apontadas na publicação, encontra-se a de "volta ao passado", que já previa as dificuldades desta geração em deixar no passado a adolescência.

(...) Essa recusa de se ligar às limitações de idade tradicionais é o que chamamos de Volta ao Passado: redefinir, para menos, o comportamento adequado a sua idade. Um novo fenômeno cultural profundo é o resultado de uma preocupação mais que inédita com a saúde e longevidade (...). Vemos isto mais como uma resposta psicossentimental realmente coletiva, alimentada em parte por uma certa arrogância da Nova Idade (1994, p. 52).

A mercadóloga também previu que a palavra-chave desta geração mesmo adulta seria "diversão" (1994, p. 55). Há impulso para voltar a ser criança, época simples onde se ria e brincava-se todo o tempo, e, conjuntamente, uma negação parcial das responsabilidades atuais. Geração com uma profunda necessidade de rir como forma compensadora do estresse e ansiedade vividos na contemporaneidade. "Procuramos alívio para o estresse com um desespero criativo - escapando fisicamente para os nossos casulos, em busca de conforto, escapando emocionalmente para as nossas fantasias, em busca de alívio" (POPCORN: 1994, p. 31.)

Está também no Relatório as tendências destes adultos a se ligarem de forma acentuada à vídeo-games como também à jogos de tabuleiros que remetiam à infância, como Detetive, Banco Imobiliário e Monopólio. A autora enfatiza que "as gerações antigas traçaram uma linha clara entre os prazeres, buscas e compras apropriadas para as crianças e as que eram apropriadas para os adultos. (...) os adultos estão agora redesenhando a linha" (1994, p. 55).

O certo para o pessoal do marketing é o seguinte: essa geração envelhecerá em grande estilo, encarando o envelhecimento e a forma como envelhecer com mais energia do que qualquer outra geração anterior. E gastará mais dinheiro do que nunca para conseguir isto (1994:56).

Segundo a autora, não há dúvidas que há uma percepção do mundo adulto, porém, "há uma sobreposição de nostalgia e uma vontade que alguém diga que o mundo ainda é um lugar maravilhoso para se viver (1994, p. 55). Um exemplo recente relacionado à tendência prevista por Faith é a campanha publicitária de grande sucesso da Coca-Cola realizada em 2011: "Os bons são a maioria”. Confira abaixo a descrição da campanha publicada no site da própria Coca-Cola: 
"A Coca-Cola estreia no Brasil um manifesto a favor do otimismo. '125 Razões para acreditar. Os bons são maioria' é o novo tema da campanha "Abra a Felicidade", que propõe uma visão positiva da vida como contraponto ao negativo. ${ }^{14}$

No filme veiculado em TV aberta e fechada, frases de otimismo reiteram a idéia: "Para cada pessoa dizendo que tudo vai piorar, 100 casais pretendem ter filhos"; "Para cada corrupto existem oito mil doadores de sangue"; "Na internet 'amor' tem mais resultados que 'medo'. Assinatura da campanha: "Existem razões para acreditar. Os bons são a maioria".

As produções cinematográficas também acabam refletindo a nostalgia da infância/adolescência intrínseca a esta geração e mais do que isto, trazem de forma reincidente como o comportamento infantil nos adultos pode ser vantajoso, divertido e criativo nas situações cotidianas, diferenciando-os dos demais adultos e principalmente, tornando a vida mais interessante: O Filme: "Quero ser grande $(1988)^{15}$ conta a estória de um menino de 12 anos que após fazer um pedido em um parque de diversões para um boneco tem seu desejo realizado: Tornar-se Adulto. Expulso de casa pela mãe por não ter sido reconhecido, começam suas aventuras. Apesar do corpo, ainda é um menino de 12 anos e esse comportamento infantil the traz grandes vantagens no mundo adulto. A diversão é a palavra chave da produção. É possível ser um adulto se divertindo como criança; "De Repente 30" (2004) ${ }^{16}$ - No dia do seu aniversário de 13 anos, garota cansada das dificuldades da idade deseja ter 30 anos. Desejo satisfeito deslumbra-se com as possibilidades e oportunidades de uma vida adulta. Além disso, acaba enfrentando com sucesso grandes desafios em sua carreira graças a sua sensibilidade adolescente de ver o mundo. A criatividade e a diversão também regem a produção; o filme "Armações do Amor" $(2006)^{17}$ acaba por sintetizar diversas características adolescentes no indivíduo adulto contemporâneo: apesar de financeiramente independente continua morando com os pais, que apresenta dificuldade em manter relacionamentos mais sérios, necessidade

\footnotetext{
${ }^{14}$ Disponível no site http://www.cocacolabrasil.com.br/release detalhe.asp?release=251\&Categoria=38. Acesso em 19/01/2012.

${ }^{15}$ O filme "Quero ser Grande" é uma comédia produzida pelo studio20th Century Fox/Gracie Films em 1988. Diretor Penny Marshall. Elenco: Tom Hanks, Elizabeth Perkins, entre outros.

${ }^{16} \mathrm{O}$ filme "De repente 30 é uma comédia produzida por Revolution Studios / Thirteen Productions LLC em 2004. direção: Gary Winick atores: Jennifer Garner, Mark Ruffalo, Judy Greer, Christa B. Allen e Andy Serkis.

${ }^{17} \mathrm{O}$ filme "Armações do Amor" foi realizado em 2006 pela produtora Paramount Pictures/Scott Rudin Productions. Direção: Tom Dey. Atores: Matthew McConaughey e Sarah Jessica Parker.
} 
da diversão e de aventura para sobrepor a rotina, etc. O roteiro insere a posição dos pais do adultescente, que cansados do filho ainda morar com eles, contrata uma psicóloga para tirá-lo de casa e incentivá-lo a prosseguir com sua vida.

Outros filmes acabam reproduzindo a fórmula tentadora de ser adolescente novamente com "Nunca Fui Beijada" (1999); “17 Outra vez” (2009), etc. Não só filmes desenvolvem seus roteiros em torno disto, mas uma infinidade de outras produções como desenhos (Simpsons e Padrinhos Mágicos, Futurama etc.) e novelas que apresentam características adultescentes intrínsecas a seus personagens.

Para a indústria cultural há neste comportamento uma forma de geração de grandes lucros, pois potencializa a criação de produtos com características híbridas, que unem formatos adultos e juvenis simultaneamente para satisfazer o público puer (como exemplos: os quadrinhos para adultos, filmes como Guerra nas Estrelas ${ }^{18}$, Avatar, jogos de vídeo-game de estratégias, coleções de miniaturas de personagens de filmes, miniaturas de carros, entre outros). Elementos esses que a pesquisadora Beatriz Sarlo identifica como substitutos da esfera pública tradicional. Além do que, esses produtos possibilitam ao adulto assumir uma persona madura sem precisar abandonar a identidade adolescente exatamente por terem sido criados para eles.

Nas produções midiáticas há fatores reincidentes: tédio, fuga de responsabilidades, conflitos geracionais, delinquência... O que pode ser considerado problemático na vida real transforma-se em pura diversão nos meios de comunicação. Um exemplo disto foi o sucesso do personagem Danilo (Alexandre Borges) na Novela Laços de Família ${ }^{19}$ que data de 2000 e que vem impingir à categoria dos adultescentes a visão de que "são eles que sabem levar a vida", e lhes dão um certo carisma dedicado às crianças que só sabem aprontar. Casado e sustentado pela milionária Alma Flora (Marieta Severo), Danilo passava seus dias entre mergulhos de piscina, flertes com empregadas, festas glamourosas e fugindo das responsabilidades entediantes. Personagem alto astral que ganhou a simpatia dos expectadores durante a trama.

\footnotetext{
${ }^{18}$ Conforme o pesquisador Rodrigo Carreiro no artigo "Identidades Culturais, Consumo e Cultura Pop em Procurando-se Amy" Os três filmes foram concebidos conscientemente para preencher uma lacuna percebida pela primeira geração de adultos com Síndrome de Peter Pan - adultos que queriam permanecer jovens. A trilogia reúne mitologia grega e misticismo budista-oriental à linguagem rápida e superficial dos seriados de TV dos anos 1930. Não à toa, os filmes de George Lucas assumem um papel de fundamental importância na afirmação social da cultura pop. Não se trata de coincidência o fato de que a trilogia de Lucas vem a fornecer referências infindáveis à trilogia de Kevin Smith. "Luke Skywalker, misto de samurai e guerreiro medieval, sábio oriental de traços juvenis, personifica a imagem do 'adultescente' perfeito".

${ }^{19}$ Laços de Família foi uma telenovela brasileira produzida e exibida pela Rede Globo de 5 de junho de

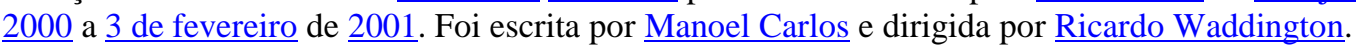


Importante destacar que o comportamento "adultescente" não reúne apenas características negativas (fuga de responsabilidades, tédio, instabilidade nos relacionamentos, etc.) como as produções midiáticas apresentam. É fato que encontramos no arquétipo do puer aeternus as polaridades comuns aos processos binários da cultura, ou seja, pólos positivo e negativo.

\begin{abstract}
A criança está sempre à frente e por trás de nós. Atrás de nós é a sombra infantil que deixamos para trás e a infantilidade que deve ser sacrificada aquilo que sempre puxa para trás levando à imaturidade, dependência, preguiça, falta de seriedade, fuga da responsabilidade e da vida. Por outro lado, se a criança que vem em nossa frente significa renovação, a possibilidade de juventude eterna, da espontaneidade e de novas possibilidades - então a vida ocorre em direção do futuro criativo. (VON FRANZ, 2005, p. 41).
\end{abstract}

Se os meios de comunicação trabalhassem só com o lado negativo do puer, nem que o eixo principal fosse a juventude, com certeza as pessoas não se identificariam com o personagem, não geraria empatia e, consequentemente, não ocorreria o esperado processo mimético que movimenta economicamente muitas indústrias.

Então há de certa forma, um padrão nas estruturas narrativas com a presença de "adultescentes": tanto em novelas como em filmes o roteiro inicia-se com o puer negativo (o ser dependente, inconseqüente, que foge das relações sérias, bom vivan) para terminar com o puer positivo (que demonstra a possibilidade de juventude eterna, porém mais responsável, bela, feliz e com um relacionamento estável).

O neuropsicólogo russo Alexander Romanovich Luria afirma que "Só por meio da ficção podemos entender a realidade"20 (2008). E a ficção tem nos trazido, conforme apontado vários estilos "adultescentes".

O fato é que a realidade vira ficção, e, pelo poder de alcance dos meios, a ficção também retroalimenta a realidade em proporções bem maiores. Esse processo se configura principalmente pela possibilidade dada ao indivíduo de acompanhar, com um certo distanciamento, narrativas onde o comportamento adultescente está inserido, refletindo a realidade e ao mesmo tempo provocando projeções e identificações.

\footnotetext{
${ }^{20}$ Conforme aula ministrada por Dr. Norval Baitello Jr. no curso de Pós Graduação de Comunicação e Semiótica da Pontifícia Universidade Católica de SP, Disciplina: As Ciências da Cultura e a Teoria da Imagem: 05/2008.
} 
Desde esta época, a vasta produção cultural que idealiza a adolescência é constantemente acompanhada pelo tema narrativo do adulto insatisfeito, querendo voltar a uma adolescência idealizada, feita de liberdade e crises salutares. (...) Essa nostalgia adulta da adolescência que atravessa a segunda metade do século, é a força atrás das mãos que nesse período desenham um série de retratos ideais de adolescentes. $\mathrm{O}$ cinema, pretendendo apresentar ou explicar o que seria a adolescência, ilustra de fato os sonhos adultos sobre a adolescência. Ele nos conta qual adolescente os adultos gostariam de voltar a ser, de ter sido ou continuar sendo. (CALLIGARIS, 2000, p.79)

A citação de Calligaris traz um fator de extrema importância para este estudo, a idéia de que a vida adolescente a qual o adulto admira, é saudosista e persegue compulsivamente é uma idealização cheia de fantasias e sonhos que na verdade nunca existiu em nenhuma adolescência vivida na realidade, apenas nas telas do cinema, da TV e de outros meios, a "imagem ideal" construída de adolescência.

Neste caso, a definição de que "imagem seria a presença de uma ausência" se estabelece perfeitamente, tendo em vista que este padrão estético e de comportamento adolescente nunca existiu, porém, sem dúvida está presente em nossa sociedade pela imagem que o consolida.

O paradoxo da imagem, de fazer presente uma ausência, funda-se essencialmente na interação entre imagem e mídia [Medium]: a imagem responde pela ausência, estando, contudo, ao mesmo tempo, presente em sua mídia portadora atual, no espaço dos vivos que são seus observadores: observar imagens significa também animá-las. (BAITELLO, 2005, p. 91)

\section{REFERÊNCIAS}

BAITELlO JR., N. O Homem que parou os relógios. São Paulo: Annablume, 1999. A Era da Iconofagia. São Paulo: Hacker Editores, 2005.

BORELLI, S.H.S; FREIRE J. (orgs.) Culturas Juvenis no Século XXI. São Paulo: Editora PUC, 2008.

CALLIGARIS, C. A Adolescência. São Paulo: Publifolha, 2000.

FRANZ, M.L. von. Puer aeternus. A luta do adulto contra o paraíso da infância. São Paulo, Paulus, 1992.

HOWE, N; STRAUSS, W. Generations: The History of America's Future. New York: William Morrow \& Company, 1991

MORIN, E. O Paradigma Perdido: A Natureza Humana. Portugal: Publicações EuropaAmérica LDA, 1990.

POPCORN, F. O Relatório Popcorn. Rio de Janeiro: Editora Campus Ltda, 1994

RODRIGUES, N. O Óbvio Ululante. São Paulo: Companhia das Letras, 1993.

SARLO, B. Cenas da Vida Pós-Moderna. Rio de Janeiro: Editora UFRJ, 1997.

Sites 
http://www.cosplay.com.br

http://jogos.uol.com.br.

http://noticias.universia.com.br.

http://www.guiasuafesta.com.br.

http://www.guiadebuffetsinfantis.com.br

http://www.cocacolabrasil.com.br

\section{Revista Impressa}

IstoÉ ed. 2005 de 04/2008 pg. 46. Seção Comportamento.

\section{Jornal Impresso}

CALLIGARIS, Contardo. "A Sedução dos Jovens". Folha de São Paulo. São Paulo, 20 de setembro de 1998, Caderno Mais!, página 4.

\section{Documentário}

REDMOND, A.M.; BIBEAU, N. Pequenos Grandes Consumidores. CBC Documentary Unit, 2006. 